\title{
Prediction of Biological Profile from Foot Dimensions: Could Body Weight and Arch Height Affect Accuracy?
}

\author{
Abdullahi Suleiman Gwani ${ }^{1^{*}}$, Adamu Ahmad Adamu ${ }^{2}$, Abubakar Tijjani Salihu ${ }^{3}$ and Adamu Ahmad Rufa'i ${ }^{4}$ \\ ${ }^{1}$ College of Medical Sciences, Abubakar Tafawa Balewa University, Bauchi State, Nigeria \\ ${ }^{2}$ Aminu Kano Teaching Hospital, Kano State, Nigeria \\ ${ }^{3}$ Hasiya Bayero Paediatric Hospital, Kano, Nigeria \\ ${ }^{4}$ College of Medical Sciences, University of Maiduguri, Borno State. Nigeria
}

"Corresponding author: Abdullahi Suleiman Gwani, Department of Human Anatomy, College of Medical Sciences, Abubakar Tafawa Balewa University, PMB 0248. Bauchi, Bauchi state, Nigeria, Tel: +2348139796989; E-mail: asgwani@yahoo.com

Received date: March 02, 2017; Accepted date: April 05, 2017; Published date: April 08, 2017

Copyright: $\odot 2017$ Gwani AS, et al. This is an open access article distributed under the terms of the Creative Commons Attribution License, which permits unrestricted use, distribution, and reproduction in any medium, provided the original author and source are credited.

\begin{abstract}
The study of human foot and its impressions has countless implications in medico-legal practice. The foot and its impressions are unique to an individual and its dimensions are known to be reliable in the prediction of biological profile. A significant number of regression equations for the prediction of biological profile are derived from foot dimensions in weight bearing living subjects. With respect to the weight applied to the foot, arches of the foot are able to deform and reverse to normal alignment, changing the shape and size of the foot. Deformities of those arches are capable of affecting the foot dimensions as well. However, from a forensic perspective, there is a paucity of literature discussing the effect of body weight and arch height on foot dimensions or their effect on the accuracy of biological profile prediction. This article, therefore, briefly discusses the forensic implication of the foot and the effect of body weight and arch height on the accuracy of the regression equations derived from weight bearing subject as well as subjects with arch deformities.
\end{abstract}

Keywords: Body weight; Arch height; Foot dimension; Prediction; Biological profile

\section{Introduction}

The study of the human foot and its impressions has countless implications in medico-legal practice [1-4]. Certainly, due to the increasing frequency of mass disasters and the likelihood of recovering isolated pedal elements in such circumstances, forensic experts may sometimes be confronted with nothing rather than foot to determine the biological profile a victim [4,5]. Indeed, the main task of a forensic podiatrist is to contribute to the establishment of personal identity through a careful examination of a pedal structure [4,6]. Establishing personal identity significantly reduces the pool of potential identities from documented missing persons [4]. Estimation of biological sex, for example, has been considered to be the initial and fundamental step for establishing the biological profile of an individual and is known to reduce the pool of possible matches by about half [7-9].

The task ahead of a forensic anthropologist has gone beyond the traditional study of human skeletal remains [10]. Undeniably, the modern roles of forensic anthropology incorporate both the study of fleshed human remains and identification of the living [10-15]. Thus, to some extent, the modern forensic anthropologist deals with soft tissue structures. For instance, a significant number of the regression equations for prediction of biological identity are derived from the living subjects in weight bearing position. Some of these equations were derived from foot dimensions with the hope that they can be useful when an isolated foot is discovered particularly as the foot dimensions have been proven to be reliable [16-19]. Surely, because of the specific legal implications attached, high accuracy and precision are required in predicting the biological profile $[11,20]$. However, there are very important sources of errors that anthropologists have not given much attention to regarding the prediction of biological profile from foot dimensions. Body weight and abnormal arch height can have profound effects on the accuracy of the regression equations derived from foot dimensions. This article, therefore, briefly discusses the forensic implication of the foot and the effect of body weight and arch height on the accuracy of the regression equations derived from weight bearing subject as well as subjects with arch deformities.

\section{An Overview of Foot Anatomy}

The foot is a complex anatomical and biomechanical structure made up of 26 bones (excluding the sesamoids), 33 articulations, 112 ligaments, and controlled by 13 extrinsic and 21 intrinsic muscles $[21,22]$. The bones comprise of 7 tarsal bones (talus, calcaneus, navicular, three cuneiforms, and cuboid), 5 metatarsals and 14 phalanges. In the frontal plane, these bones have been divided into three anatomical and functional zones: the hindfoot (talus and calcaneus), separated from the midfoot (navicular, cuboid and cuneiforms) by the transverse tarsal joint, and forefoot (metatarsals and phalanges), separated from the midfoot by tarsometatarsal joint [23]. The sagittal plane division divides the foot into a more flexible medial column (consisting of the talus, navicular, three cuneiforms, and first three metatarsals) and lateral column (consisting of the calcaneus, cuboid, and lateral two metatarsals) [24].

The architecture of the foot is such that its bones do not lie in the same horizontal plane. Rather, their shapes and configuration form a dome relative to the ground, forming the longitudinal and transverse arches of the foot [25]. The bones are united and supported by the ligaments, which are of varying length, width, and elasticity, permitting 
small to a large degree of movements of the joints around the arches. The ligaments, in combination with the muscles and tendons, confer a considerable flexibility to the foot, allowing the arches to deform and reverse to normal alignment with respect to the load applied. Through this configuration, the foot is able to absorb body weight as well as counter gravity and shocks injurious to the skeletal structures of the body [26]. On the other hand, the general shape and size of the foot, as well as the impression made by the foot, depends upon the structure of the different bones comprising the foot. The way the bones are held by the connective tissues also differs, not only from individual to individual but also from left to right feet of the same individual $[2,26-28]$. The foot is also affected by racial and regional variations, age, gender, lifestyle, nutritional status, shoe type as well as congenital and climatic factors $[29,30]$.

The longitudinal arch of the foot consists of a medial and a lateral part. Clinically, and perhaps forensically, the medial longitudinal arch is the most important of all arches of the foot; it is the chief loadbearing structure in the foot [31]. The arch extends longitudinally from the tuberosity on the plantar surface of the calcaneus posteriorly to the heads of the $1 \mathrm{st}, 2^{\text {nd }}$ and $3^{\text {rd }}$ metatarsals anteriorly. Based on the morphology of the medial longitudinal arch, foot posture has been classified into three: i) a normal (normally aligned) foot, ii) low-arched (pronated or flat) foot in which the arch height is below the normal range with the medial side of the foot coming into complete or nearcomplete contact with the ground, and iii) high-arched (supinated) foot in which the height of the medial longitudinal arch is abnormally high.

\section{Body Weight, Arch Height and Foot Dimensions}

Being the most distal part of the body, the foot serves as the primary interface between the ground and body [32], and the site at which external forces are applied to the body [33]. Consequent to the forces acting on the foot from body weight and gravity, the size, and shape of the foot is altered during weight-bearing compared to that of the nonweight-bearing foot (Figure 1) [4]. In fact, Krishan [34] noted that both length and breadth of footprint tend to increase significantly with an increase in $20 \mathrm{~kg}$ weight.

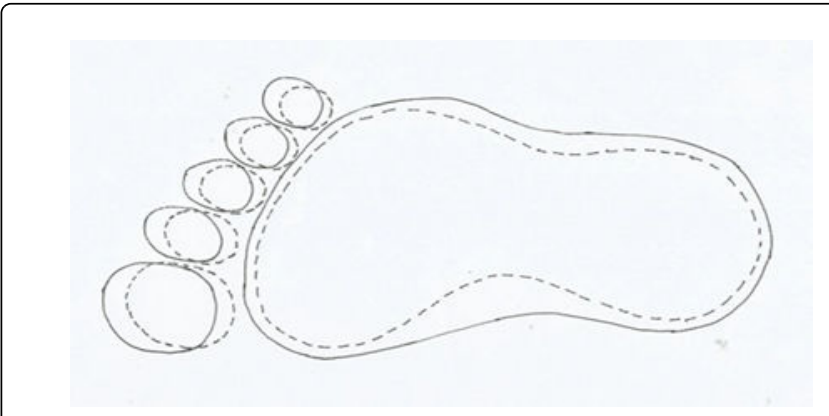

Figure 1: A schematic diagram showing the effect of body weight on footprint dimensions. In a non-weight-bearing foot, the footprint is shorter and narrower (dotted lines) whereas, in a weight-bearing foot, the footprint is longer and wider (continuous lines).

Additionally, Uhrova, Benus [35] observed that the body weight of standing individual compresses the foot and press it against the floor, whereas in lying position, no force is acting upon the foot so the foot dimensions will be smaller than the actual dimensions in the standing position. Thus, a forensic scientist using regression equation derived from standing living subjects must take into account the weight bearing changes that occur in the foot [35].

The concept of the foot as a twisted plate presented by Sarrafian [36] explains the principles of lengthening and shortening of the foot respectively in weight-bearing and non-weight-bearing postures as well as in low-arched and high-arched foot. Twisting the foot plate further, as in high-arched foot, increases the height of the medial longitudinal arch, shortens the foot length, and relaxes the plantar fascia (Figure 2). Untwisting the foot plate, which mimics a low-arched foot, lowers the medial longitudinal arch, lengthens the foot, and tenses the plantar fascia (Figure 3). Indeed, it has been observed that the skeleton of the foot rests on, and is controlled by, a multisegmental ligamentous and fascial tie-bar system formed respectively by the deep transverse metatarsal ligament and the plantar fascia [37]. The fascia is attached posteriorly to the inferior aspect of the calcaneal tuberosity and extends anteriorly to the base of the proximal phalanx of each toe, acting as tie-bar to control the longitudinal arch of the normal weightbearing foot.

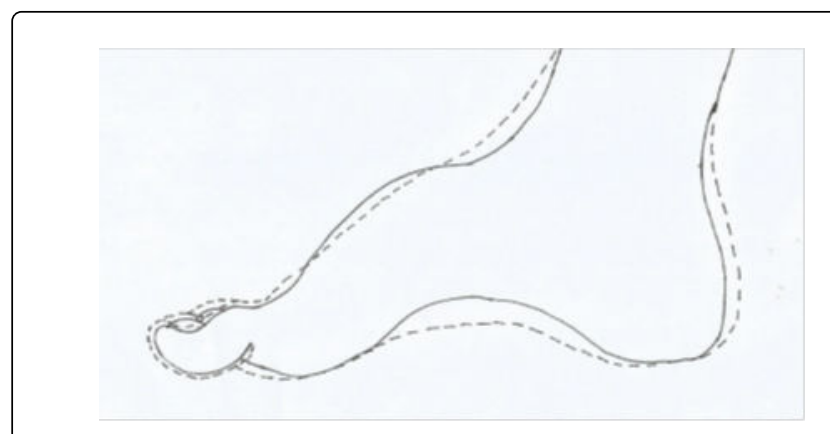

Figure 2: A schematic diagram of a normal foot (dotted lines) and a high arched foot in which the arch is higher and the foot is shorter (continuous lines).

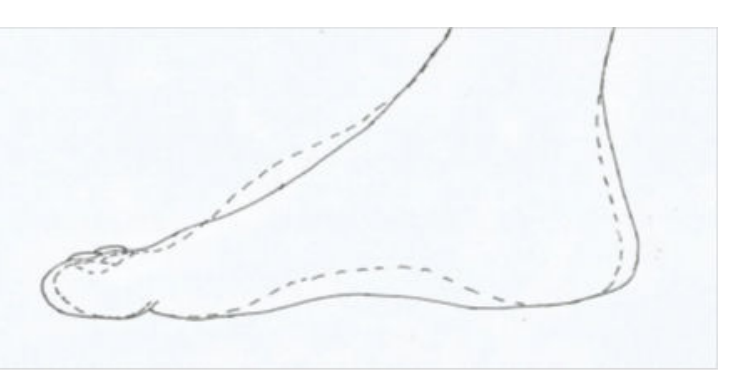

Figure 3: A schematic diagram of a normal foot (dotted lines) and a low-arched foot in which the arch is lower and the foot is longer (continuous lines).

In an earlier study, Hicks [38] observed that, in a normal living foot that is weight-bearing, as in ordinary standing, passive dorsiflexion of the toes at the metatarsophalangeal joints result in the proximal phalanges sliding onto the dorsum of the metatarsal heads and pulling after them the plantar pad which subsequently came to lie anterior to the metatarsal heads and this in turn pull upon the attached processes of the plantar fascia, shortening distance between the calcaneus and the metatarsal heads. Thus, the process winds the plantar fascia around the metatarsal heads. Consequently, the plantar fascia becomes tensed with a tight band appearing in the plantar aspect of the foot, the arch 
becomes shorter and higher (Figure 4). Indeed, several studies have shown the significance of plantar fascia in maintaining the shape of the longitudinal arch as well as the foot in general [39-42]. The plantar fascia provides the highest relative contribution to arch stability, followed by long and short plantar ligaments and plantar calcaneonavicular ligament [43]. In fact, the evolution of the human longitudinal arch was itself thought to be partly due to shortening of such connective structures as the plantar fascia, the long plantar ligament and the plantar calcanceonavicular ligament [44].

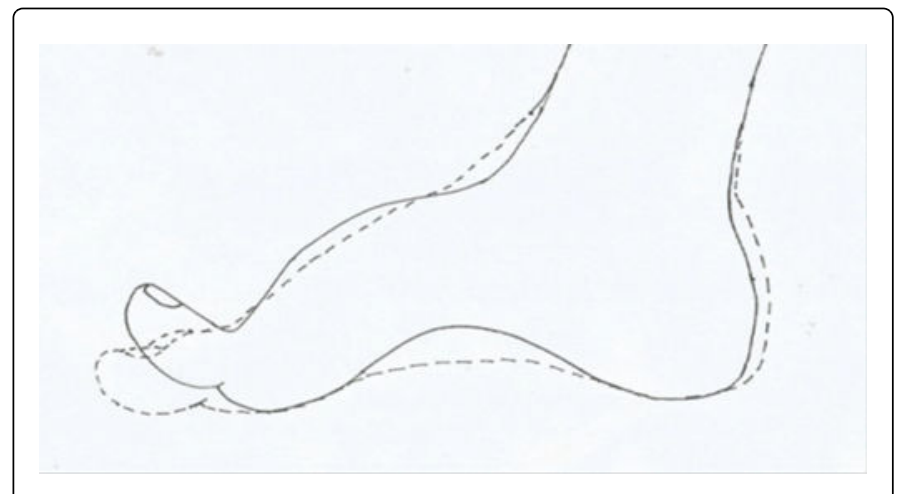

Figure 4: A schematic diagram of a living foot, standing (dotted lines). When the toes are dorsiflexed, the arch becomes shorter and higher and thus decrease in foot length (continuous lines).

The measurement of actual foot length can also be skewed by foot deformities such as claw toes and hallux valgus. Claw toes are sometimes found in individuals with high-arched foot, whereas hallux valgus is often found in individuals with a low-arched foot [45]. Hallux valgus results in failure of the hallux windlass mechanism. Subsequently, control and support of the medial longitudinal arch are reduced or lost and thus decrease in arch height. Consequently, the foot may be longer than normal. In claw toes, on the other hand, the metatarsophalangeal joints are further dorsiflexed, the metatarsal heads further depressed, and the plantar fascia further tightened. Thus, the arch becomes higher and the distance between the metatarsal heads and the calcaneus further shortens, and thus, reduction in the foot length [37].

Nevertheless, some studies have shown that no meaningful relationship exists between arch height and foot length [46-48]. Additionally, one study that categorized foot posture into normal, lowarched and high-arched feet using arch index derived from inked footprint reported no significant differences in foot length, stature, body weight and body mass index between the three categories [49]. However, these studies were primarily based on the applicability of foot dimensions in footwear design. Forensically, however, the influence of the different arch height on the accuracy of regression equations derived from individuals with the three different foot postures has not been reported according to our search. A study by Zeybek et al. determined regression equation for estimation of stature and gender from four foot dimensions, including navicular height. The navicular height, in particular, showed a good relationship with the stature. Interestingly, the height of the navicular bone is known to be proportional to arch height and this makes it a suitable reference point in examinations of arch deformities [50]. Indeed, Xiong [49] also observed that the low-arched group have significantly smaller navicular height and longer arch length compared to the normal and high-arched groups.
It is an established fact that both foot length and the navicular height tend to increase with an increase in age [51]. Indeed, the growth of the foot is in synchrony with the body as a whole since the human stature is an anatomical complex of linear dimensions [52]. Thus, the relationship between the navicular height and the stature reported by Zeybek and Ergur [29] may be considered as part of the normal growth process where the various body parts increase proportionately [35]. From the statistical viewpoint, however, it may be understood that because of the positive correlation existing between the stature and navicular height, an increase in navicular height results in an increase in arch height and stature as well. Thus, when deriving a regression equation from individuals with low-arched feet, the stature may be erroneously estimated, as the arch height has abnormally decreased, the foot length abnormally increased while the stature remains normal. Similarly, errors may result when regression equation derived from individuals with high-arched feet is used to estimate stature, since the arch height has abnormally increased, and the foot length decreased while the stature remains normal.

\section{Conclusion}

This article briefly reviewed the forensic implication of the foot and the effect of body weight and arch height on the accuracy of regression equations derived from weight bearing living subjects as well as subjects with arch deformities. Body weight causes significant changes in the foot shape which may compromise the accuracy of regression equations derived. In weight bearing or low-arched foot, the foot length slightly increases higher than normal whereas, in a high-arched foot, the foot length is shorter than normal. Thus, forensic scientists, as well as researchers, should take into account the possible effects of body weight and foot posture in forensic investigations where regression equations derived from foot dimensions are to be used. However, further studies that group subjects into normal, low-arched and high-arched feet to compare the integrity of the regression equations derived from the different groups are recommended.

\section{References}

1. Krishan K, Kanchan T, Passi N (2011) Estimation of stature from the foot and its segments in a sub-adult female population of North India. J Foot Ankle Res 4: 24.

2. Krishan K, Kanchan T, DiMaggio JA (2015) Emergence of forensic podiatry--A novel sub-discipline of forensic sciences. Forensic Sci Int 255: 16-27.

3. Robinson C, Eisma R, Morgan B, Jeffery A, Graham EA et al. Anthropological measurement of lower limb and foot bones using multidetector computed tomography. J Forensic Sci 53: 1289-1295.

4. Davies CM, Hackman L, Black SM (2014) The foot in forensic human identification - a review. Foot (Edinb) 24: 31-36.

5. Davies C, Hackman L, Black S (2013) A test of the Whitaker scoring system for estimating age from the bones of the foot. Int J Leg Med 127: 481-489.

6. Kanchan T, Krishan K, ShyamSundar S, Aparna KR, Jaiswal S (2012) Analysis of footprint and its parts for stature estimation in Indian population. Foot (Edinb) 22: 175-180.

7. Scheuer L (2002) Application of osteology to forensic medicine. Clin Anat 15: 297-312.

8. Zakaria MS, Mohammed AH, Habib SR, Hanna MM, Fahiem AL (2010) Calcaneus radiograph as a diagnostic tool for sexual dimorphism in Egyptians. J Forensic Leg Med 17: 378-382.

9. Krishan K, Chatterjee PM, Kanchan T, Kaur S, Baryah N, et al. (2016) A review of sex estimation techniques during examination of skeletal 
remains in forensic anthropology casework. Forensic Sci Int 261: 165e1e8.

10. Cattaneo C (2007) Forensic anthropology: Developments of a classical discipline in the new millennium. Forensic Sci Int 165: 185-193.

11. Cunha E, Baccino E, Martrille L, Ramsthaler F, Prieto J, et al. (2009) The problem of aging human remains and living individuals: a review. Forensic Sci Int 193: 1-13.

12. Adams BJ, Herrmann NP (2009) Estimation of living stature from selected anthropometric (soft tissue) measurements: applications for forensic anthropology. J Forensic Sci 54: 753-760.

13. Franklin D (2010) Forensic age estimation in human skeletal remains current concepts and future directions. Leg Med (Tokyo) 12: 1-7.

14. Sen J, Ghosh S (2008) Estimation of stature from foot length and foot breadth among the Rajbanshi: An indigenous population of North Bengal. Forensic Sci Int 181: 55.

15. Hemy N, Flavel A, Ishak NI, Franklin D (2013) Estimation of stature using anthropometry of feet and footprints in a Western Australian population. J Forensic Leg Med 20: 435-441.

16. Gwani AS, Salihu AT, Garba IS, Rufa'i AA (2017) Estimation of stature from radiographic measurement of foot dimensions: Truncated foot length may be more reliable than full foot length. J Forensic Leg Med 46: 53-57.

17. Nor FM, Abdullah N, Mustapa AM, Qi Wen L, Faisal NA, et al. (2013) Estimation of stature by using lower limb dimensions in the Malaysian population. J Forensic Leg Med 20: 947-952.

18. Ahmed AA (2013) Estimation of sex from the lower limb measurements of Sudanese adults. Forensic Sci Int 229: 169.

19. Ahmed AA (2013) Estimation of stature using lower limb measurements in Sudanese Arabs. J Forensic Leg Med 20: 483-488.

20. Aziz KS, Mahmood M (2016) Beyond DVI: Future Identification, Research and Archiving. j Forensic Res 7: 359.

21. Hillstrom HJ, Song J, Kraszewski AP, Hafer JF, Mootanah R, et al. (2013) Foot type biomechanics part 1: Structure and function of the asymptomatic foot. Gait Posture 37: 445-451.

22. Fukano M, Fukubayashi T (2009) Motion characteristics of the medial and lateral longitudinal arch during landing. Eur J Appl Physiol 105: 387-392.

23. Wicart P (2012) Cavus foot, from neonates to adolescents. Orthop Traumatol Surg Res 98: 813-828.

24. Seringe R, Wicart P; French Society of Pediatric Orthopaedics (2013) The talonavicular and subtalar joints: the "calcaneopedal unit" concept. Orthop Traumatol Surg Res 99: S345-355.

25. Nurzynska D, Meglio FD. Castaldo C, Latino F, Romano V, et al. (2012) Flatfoot in children: Anatomy of decision making. Ital J Anat Embryol 117: 98-106.

26. Kennedy RB (1996) Uniqueness of bare feet and its use as a possible means of identification. Forensic Sci Int 82: 81-87.

27. Krishan K (2007) Individualizing characteristics of footprints in Gujjars of North India--forensic aspects. Forensic Sci Int 169: 137-144.

28. Menz HB (2004) Two feet, or one person? Problems associated with statistical analysis of paired data in foot and ankle medicine. The Foot 14: 2-5.

29. Zeybek G, Ergur I, Demiroglu Z (2008) Stature and gender estimation using foot measurements. Forensic Sci Int 181: 54.

30. Braun S, Basquin L, Mery C (1980) The contour of the normal foot. A statistical study. Rev Rhum Mal Osteoartic 47: 127-133.
31. Glasoe WM, Yack HJ, Saltzman CL (1999) Anatomy and biomechanics of the first ray. Phys Ther 79: 854-859.

32. Young CC, Niedfeldt MW, Morris GA, Eerkes KJ (2005) Clinical examination of the foot and ankle. Prim Care 32: 105-132.

33. Pohl MB, Farr L (2010) A comparison of foot arch measurement reliability using both digital photography and calliper methods. J Foot Ankle Res 3: 14

34. Krishan K (2008) Establishing correlation of footprints with body weight--forensic aspects. Forensic Sci Int 179: 63-69.

35. Uhrovaj P, Beauaj R, Masnicovaj S, Obertova $\mathrm{Z}$, Kramajrovaj D, et al. (2015) Estimation of stature using hand and foot dimensions in Slovak adults. Leg Med (Tokyo) 17: 92-97.

36. Sarrafian SK (1987) Functional characteristics of the foot and plantar aponeurosis under tibiotalar loading. Foot Ankle 8: 4-18.

37. Stainsby GD (1997) Pathological anatomy and dynamic effect of the displaced plantar plate and the importance of the integrity of the plantar plate-deep transverse metatarsal ligament tie-bar. Ann R Coll Surg Engl 79: 58-68.

38. Hicks JH (1954) The mechanics of the foot. II. The plantar aponeurosis and the arch. J Anat 88: 25-30.

39. Yang SM (1985) Dynamic changes of the arches of the foot during walking. Acta Med Nagasaki 30: 93-112.

40. Arangio GA, Chen C, Salathé EP (1998) Effect of varying arch height with and without the plantar fascia on the mechanical properties of the foot. Foot Ankle Int 19: 705-709.

41. Caravaggi P, Pataky T, Günther M, Savage R, Crompton R (2010) Dynamics of longitudinal arch support in relation to walking speed: Contribution of the plantar aponeurosis. J Anat 217: 254-261.

42. McNally EG, Shetty S (2010) Plantar fascia: Imaging diagnosis and guided treatment. Semin Musculoskelet Radiol 14: 334-343.

43. Huang CK, Kitaoka HB, An KN, Chao EY (1993) Biomechanical evaluation of longitudinal arch stability. Foot Ankle 14: 353-357.

44. Elftman H, Manter J (1935) The Evolution of the Human Foot, with Especial Reference to the Joints. J Anat 70: 56-67.

45. Williams DS, McClay IS (2000) Measurements used to characterize the foot and the medial longitudinal arch: reliability and validity. Phys Ther 80: 864-871.

46. Hill M, Naemi R, Branthwaite H, Chockalingam N (2017) The relationship between arch height and foot length: Implications for size grading. Appl Ergon 59: 243-250.

47. Xiong S, Goonetilleke RS, Witana CP, Lee Au EY (2008) Modelling foot height and foot shape-related dimensions. Ergonomics 51: 1272-1289.

48. Li J (2005) Analysis of foot shape measured from Chinese male and female adults. In: Proceedings 7th footwear biomechanics symposium, Cleveland, USA.

49. Xiong S, Goonetilleke RS, Witana CP, Weerasinghe TW, Lee Au YM (2010) Foot arch characterization: A review, a new matric and a comparison. J Am Podiatr Med Assoc 100: 14-24.

50. Roth S, Roth A, Jotanovic Z, Madarevic T (2013) Navicular index for differentiation of flatfoot from normal foot. Int Orthop 37: 1107-1112.

51. Waseda A, Suda Y, Inokuchi S, Nishiwaki Y, Toyama Y (2014) Standard growth of the foot arch in childhood and adolescence--derived from the measurement results of 10,155 children. Foot Ankle Surg 20: 208-214.

52. Ho TY, Ou SF, Huang SH, Lee CN, Ger LP, et al. (2009) Assessment of growth from foot length in Taiwanese neonates. Pediatr Neonatol 50: 287-290. 